\title{
Sustainable Development Planning in Agriculture: Development and utilization of an Integrated Information System
}

\author{
O. R. Sulaja ${ }^{1 *}$ and Jiju P. Alex ${ }^{2}$ \\ ${ }^{1}$ Department of Agricultural Extension, ${ }^{2}$ Director of Extension, College of Agriculture, Kerala \\ Agricultural University, Thrissur, Kerala, India \\ *Corresponding author
}

A B S T R A C T

Keywords

integrated

information system,

Extension

Personnel, People's

Representatives,

micro level

planning,

agriculture, Kerala

Article Info

Accepted:

12 May 2021

Available Online:

10 June 2021
Agricultural development planning adopts bottom up approach for area specific, problem centered effective planning through democratic decentralized planning process in the state of Kerala, India. Efficiency of this micro level planning process necessitates the use of micro level data bases which are reliable and credible. The study attempted to evolve specifications of an 'Integrated Information System in Agriculture' which suggested the development of comprehensive databases for different processes of development planning right from project plan formulation to implementation and evaluation. Fourteen different domains of knowledge/ data components have been identified which are interrelated. The study also attempted to analyse the perception of Extension Personnel and People's Representatives on the importance of proposed Integrated Information System. Extension Personnel and People's Representatives consist of the major stakeholders in micro level planning process, hence their perception on four identified dimensions of Integrated Information System was also studied. The dimension 'usability' was perceived as the most important dimension by both stakeholders followed by 'comprehensiveness', 'spatial and temporal orientation' and 'updatability'.

\section{Introduction}

Agriculture development requires planning at the micro level as it is highly contextual and location specific. Micro level planning is a dynamic process which involves planning at the grassroots level taking each individual, family and category of the community of a given area. Micro level planning in agriculture is information intensive (GOK, 2009), so also planning processes in other sectors. Planners and other stakeholders have to depend on different sources of information to facilitate at least the key processes involved in decentralized planning process. Apart from advanced technical information and new information on procedures, schemes and policies that are dynamically obtained from different government agencies from time to time, all other vital information are obtained 
from existing sources viz., the legacy registers kept in offices.

Pointing to the key functions of micro level planning, Ghosh et al., (2011) describes micro level planning as one of the key factors in rural development and sustainable resource management. Information is described as a raw material by Harande (2009). Also opined that rural and urban dwellers use information for their development. A nation's progress, prosperity and development is directly related to its ability to acquire, produce, access, and use relevant information. Expressing concern over the constraints involved in obtaining data support for planning at the micro level, Harilal (2012) insists that there should be efforts by government machinery to collect and store data on local governments and local level planning. This should expedite planning process instead of acting as an impediment. Ghosh et al., (2011), Issac and Franke (2002), Jackson-Smith (2002) and Moni (2010) listed different types of data to be included in Agricultural Resources Information System. Discussing the pre requisites of e-governance support for local development, Alex (2011) pointed out the lacunae in data management systems in local bodies and explained the need to digitize local registers and databases for providing database support for local bodies to make decisions on development issues and projects at the grassroots level. NIC (2014) also advocates the need to build a comprehensive database at the district, block and village level to meet the growing demand of information for planning purposes. The study was undertaken with the specific objectives of developing the specifications of an Integrated Information System with complete list of information items required for entire process of micro level planning. The study also attempted to find out the perceptual differences between Extension Personnel and People's Representatives regarding the importance of different dimensions of an integrated information system.

\section{Materials and Methods}

The study was administered in Kerala State, India. The selection of respondents was made using the statistical method of multi stage random sampling. This method was repeated for selection of local self government institutions. Northern, Southern, Central, High altitude and Problem area were the five identified agro climatic zones of Kerala State. One district each from these zones and one district from Onattukara region were selected for this study. Random selection was followed for identifying two blocks each from these six districts, and four Grama Panchayats from these respective blocks. The respondents of the study comprised of (i) Officers of the Department of Agriculture working with the Grama Panchayats, Block Panchayats and District Panchayats at the rate of one from each local body selected (66 officers).

Another set of respondents were (ii) People's representatives at Grama Panchayats, Block Panchayats and District Panchayats at the rate of one from each local body (66 people's representatives). Both these groups constituted an aggregate of 132 respondents. Perception on integrated information system for micro level planning has been measured under four dimensions viz. comprehensiveness, usability, updatability, spatial and temporal orientation. In order to measure these dimensions, 60 statements were formulated under different dimensions and they were subjected to relevancy rating by a panel of judges. Thurstone scale was used to finalise the questionnaire with 20 statements. The responses of Extension Personnel and People's Representatives were collected along a five point continuum with scores of 5,4,3,2 and 1 for strongly agree, moderately agree, slightly agree, slightly disagree and strongly disagree respectively. 


\section{Results and Discussion}

\section{Components of an Integrated Information System in Agriculture}

An investigation of data requirements and detecting the assortment of information is vital in instigating an 'integrated information system' for development planning in agriculture. Efforts were made to explore type of information used and demanded at different phases of decentralized planning by important contributors. Comprehensive cataloguing of total information requirement was accomplished by extracting data from various project reports affiliated to various development micro sectors and administering focus group discussions with resource persons.

The process of decentralized planning followed in Kerala State was studied in detail to find out the different stages where data requirement is inevitable for effective planning. Formation of working groups for situation analysis and participatory resource appraisal is the first step of planning process. The geographic features of the locality, natural resources, details of projects, details of beneficiaries, physical and financial targets to be accomplished are important data components required at this stage. Village councils (Grama sabhas) are to be conducted for citizen consultation. This stage is followed by projectisation by implementing agency. Panchayat development seminars will be administered for consolidation of project ideas. Plan finalization will be done as the next step after getting approval by the local body, this will be approved by expert committees also. District planning committee will give administrative sanction to the project for implementation by respective agencies. Participatory monitoring and evaluation is the final step in this process. Various stakeholders involved in planning process viz. panchayat officials, agricultural personnel and peoples' representatives at various hierarchical levels were taken as respondents for eliciting data items. All the available records of project formulation were analysed meticulously to arrive at the overall information requirement. The information components which may be useful for micro level planning, has been categorized into 14 sub headings. This include information items on natural resources (land, water, soil), climate, demographic characteristics etc. as seen in Table 1.

A perusal of table 1 indicated that, 233 information items were documented under different domains which will be useful in micro level planning process. About 21.89 per cent of information items were pertaining to land which included data on land area, land utilization pattern, land use and mining. The information items on water and soil comprised of 6 per cent and 3 per cent respectively. It is inferred that 30.89 per cent of information items required for micro level planning is pertaining to natural resources obviously the most important resource in development planning. The information items on crops constituted 13.73 per cent followed by information on institutions $(9.02 \%)$. The percentage shares of other items are less but play significant role while seeking information. The information items for the proposed integrated information systems in agriculture were collected from different government sources. The source wise distribution of information is given in the Table 2 below.

It is evident from the Table 2 that, 33 per cent of information was provided by Grama Panchayat and District Panchayat. It is followed by Department of Agriculture and Krishi Bhavan (28 \%). Soil Survey Department contributes 10 per cent of the information items whereas Land Use Board provides nine per cent of the same. The domestic legislation for democratic 
decentralization in Kerala had provisions to empower the three tier system of local governance. Three tiers were constituted by District panchayat at the top level, Block panchayat in the middle and Gram panchayat at the bottom line. The gram panchayat office collect and keep all information about people residing under its jurisdiction, right from birth registration to death registration, receipts and expenditure of the panchayat, number of roads by type and length, number of public taps, ponds, wells by ward, no. of street lamps, buildings and houses by types, no. of voters, vital statistics, types of institutions, list of merchants. Block panchayat compiles data from all gram panchayats whereas District panchayat records and keeps all primary data provided by these institutions at grass roots level.

Krishi bhavan provide data on Cropping pattern, production and productivity of crops, fertilizer and pesticide use, soil quality, irrigation, distribution of farms by land use. While examining the data sources, we could see that 61 per cent of required data is being provided by the duo (panchayat and department of agriculture). The data fields preserved by Soil Survey Department are slope, erosion, vegetative cover, agricultural land percentage, soil characters, hydrologic group, rock outcrops, stoniness, socio economic condition, water, climate and digital data processing.

The other contributing sources were Ground Water Department (4\%), Indian Meteorological Department (3\%), Kerala Agricultural University (5\%), Veterinary Department, Village Office, Fisheries Department, Forest Department etc. About six per cent of the data components/ information items required for micro level planning were not readily available to provide pertinent information. Land Use Board generate cadastral maps of 1:5000 scale including survey number and soil characteristics, thematic maps on land use, details of water resources, forest area, Mahatma Gandhi National Rural Employment Guarantee Scheme (MGNREGS) workers, land use map of whole Kerala State, Maps on assets, land capability map, micro level watershed atlas, maps on geo morphological units at 1:50000 scale, river basins etc. Village office is the one keeping record of details of all land, details of owner, acreage of garden land, wet land, fallow land, amount of tax, details of tax and address, Survey no., name and address, amount remitted, map with survey no. of plots, schools, ponds etc, field map, litho map, register for luxury tax, register of surveyor etc.

\section{Integrated Information System in agriculture}

Integrated information system in agriculture is envisaged as an information system which is capable of providing the user with comprehensive information required for agricultural planning, which is oriented on spatial and temporal levels; and could be timely updated.

A new framework is suggested for a prospective Integrated Information System in Agriculture which can be used for obtaining access to various data and information for ideal micro level planning in the context of decentralized planning. A pictorial representation of the framework suggested is provided as Fig. 1.

The conceptual framework gives possible linkages among the different domains of data/ information required for micro level planning in agriculture. An integrated information system would contain data sources of all these domains logically linked together so as to enable the user to draw useful information as and when required. The possibility of linkages between different domains is depicted in the 
form of lines connecting each domain with the other. The lines do not represent the degree of importance or direction of relationship. Instead, they indicate only the logical linkages between different types of data. These databases can be spatially oriented to find out the specific location and the unique interactions required in each location.

Overall information requirement of stakeholders in micro level planning

An analysis was carried out to find out the relative importance of different components of 'integrated information system' in the process of micro level planning. The components are given ranking based on the scores ascribed by respondents for all the components. Fourteen domains of information which were identified to be useful for micro level planning were further elaborated into 16 sub headings. The item natural resources were divided into land, water and soil while depicting in the graph. The scores representing the importance of a category was calculated by summing up the scores ascribed to the category by all the respondents.

The pattern of information requirement of the respondents viz. Extension Personnel and People's Representatives together is depicted in Fig. 2. The graph shows that information on government policies was perceived as the most important information used for micro level planning. Government policies of the central government and state government changes periodically, hence formulating programmes according to government policies become inevitable. This may be reason for perceiving it as the most important one. Data on government programmes for agricultural development was perceived as the next important one followed by project monitoring data. The priority areas marked for particular project year vary according to the government policies. Fixing of government programmes and funding for these programmes will be decided considering so many factors. Extension personnel and people's representatives will have to consider these elements during micro level planning process. The stakeholders mark their perception on importance of data items from their experience on micro level planning. The fourth most important one was the data on crops. It was followed by data on water, information on existing perspective plans, soil respectively in the order of the importance cited by respondents.

Comparative analysis of perception of Extension Personnel and People's Representatives on different dimensions of 'Integrated Information System for Micro Level Planning in Agriculture'

Perception on integrated information system for micro level planning has been measured under four dimensions viz. comprehensiveness, usability, updatability, spatial and temporal orientation. The perception of stakeholders on different dimensions was examined to find out the relative relevance of each dimension. It would also indicate the most desired attribute of an integrated information system for planning agricultural development (Table 3).

Perception of Extension Personnel as regards the four dimensions viz, comprehensiveness, usability, updatability and spatial and temporal orientation, were assessed by Kendall's W, which showed that Extension Personnel had a greater degree of unanimity among the various responses regarding the relative importance of four dimensions. 
Table.1 Components of an Integrated Information System in Agriculture

\begin{tabular}{|c|c|c|c|}
\hline Sl.No. & Major components & $\begin{array}{c}\text { No. of items under } \\
\text { each component }\end{array}$ & Percentage \\
\hline $\mathbf{1 . 1}$ & Land & 51 & 21.89 \\
\hline $\mathbf{1 . 2}$ & Water & 14 & 6.00 \\
\hline $\mathbf{1 . 3}$ & Soil & 7 & 3.00 \\
\hline $\mathbf{2}$ & Climate & 8 & 3.44 \\
\hline $\mathbf{3}$ & Demographic data & 11 & 4.72 \\
\hline $\mathbf{4}$ & Socio-economic characteristics & 20 & 8.59 \\
\hline $\mathbf{5}$ & Crops & 32 & 13.73 \\
\hline $\mathbf{6}$ & Technology & 14 & 6.00 \\
\hline $\mathbf{7}$ & Details of infrastructure & 19 & 8.16 \\
\hline $\mathbf{8}$ & Mechanization & 6 & 2.58 \\
\hline $\mathbf{9}$ & Institutions & 7 & 9.02 \\
\hline $\mathbf{1 0}$ & Market & 10 & 3.00 \\
\hline $\mathbf{1 1}$ & Government policies & 5 & 4.29 \\
\hline $\mathbf{1 2}$ & Government programmes and schemes & & 2.15 \\
\hline & for agricultural development & 4 & 1.71 \\
\hline $\mathbf{1 3}$ & Project monitoring & $\mathbf{2 3}$ & 1.71 \\
\hline $\mathbf{1 4}$ & Existing perspective plans & & $\mathbf{1 0 0}$ \\
\hline & Total & & \\
\hline
\end{tabular}

Table.2 Information sources for the content on 'Integrated Information System for Micro Level Planning in Agriculture'

\begin{tabular}{|c|c|c|}
\hline SI.No. & Agencies providing information & Percentage of information \\
\hline $\mathbf{1}$ & Grama Panchayat and District Panchayat & 33 \\
\hline $\mathbf{2}$ & Department of Agriculture, Krishi Bhavan & 28 \\
\hline $\mathbf{3}$ & Soil Survey Department & 10 \\
\hline $\mathbf{4}$ & Land Use Board & 9 \\
\hline $\mathbf{5}$ & Ground Water Department & 4 \\
\hline $\mathbf{6}$ & Indian Meteorological Department & 3 \\
\hline $\mathbf{7}$ & Kerala Agricultural University & 5 \\
\hline $\mathbf{8}$ & Village Office & 2 \\
\hline $\mathbf{9}$ & District Census Handbook & 2 \\
\hline $\mathbf{1 0}$ & Other sources (Fisheries, Veterinary, KILA, Forest, & 5 \\
\hline $\mathbf{1 1}$ & Electricity Board, Market Intelligence Bureau etc.) & 6 \\
\hline
\end{tabular}

(Multiple responses, not to total) 
Table.3 Relative importance of the dimensions of an 'Integrated Information System for Micro Level Planning in Agriculture' as perceived by Extension Personnel and People's

Representatives

\begin{tabular}{|c|c|c|c|c|c|}
\hline \multirow{2}{*}{$\begin{array}{c}\text { Sl. } \\
\text { No. }\end{array}$} & Dimension & \multicolumn{2}{|c|}{ Extension Personnel (N=66) } & \multicolumn{2}{|c|}{$\begin{array}{c}\text { People's } \\
\text { Representatives(N=66) }\end{array}$} \\
\cline { 3 - 5 } & & Mean rank & Kendall's W & Mean rank & Kendall's W \\
\hline $\mathbf{1}$ & Comprehensiveness & $2.78^{\mathrm{b}}$ & & $2.95^{\mathrm{b}}$ & \\
\hline $\mathbf{2}$ & Usability & $3.75^{\mathrm{a}}$ & & $3.93^{\mathrm{a}}$ & \multirow{2}{*}{$0.943^{* *}$} \\
\hline $\mathbf{3}$ & Updatability & $1.09^{\mathrm{d}}$ & $0.764^{* *}$ & $1.02^{\mathrm{d}}$ & \\
\hline $\mathbf{4}$ & $\begin{array}{c}\text { Spatial \& temporal } \\
\text { orientation }\end{array}$ & $2.38^{\mathrm{c}}$ & & $2.11^{\mathrm{c}}$ & \\
\cline { 5 - 6 } & & & & \\
\hline
\end{tabular}

Fig.1 Conceptual framework of proposed Integrated Information System for Micro Level Planning in Agriculture

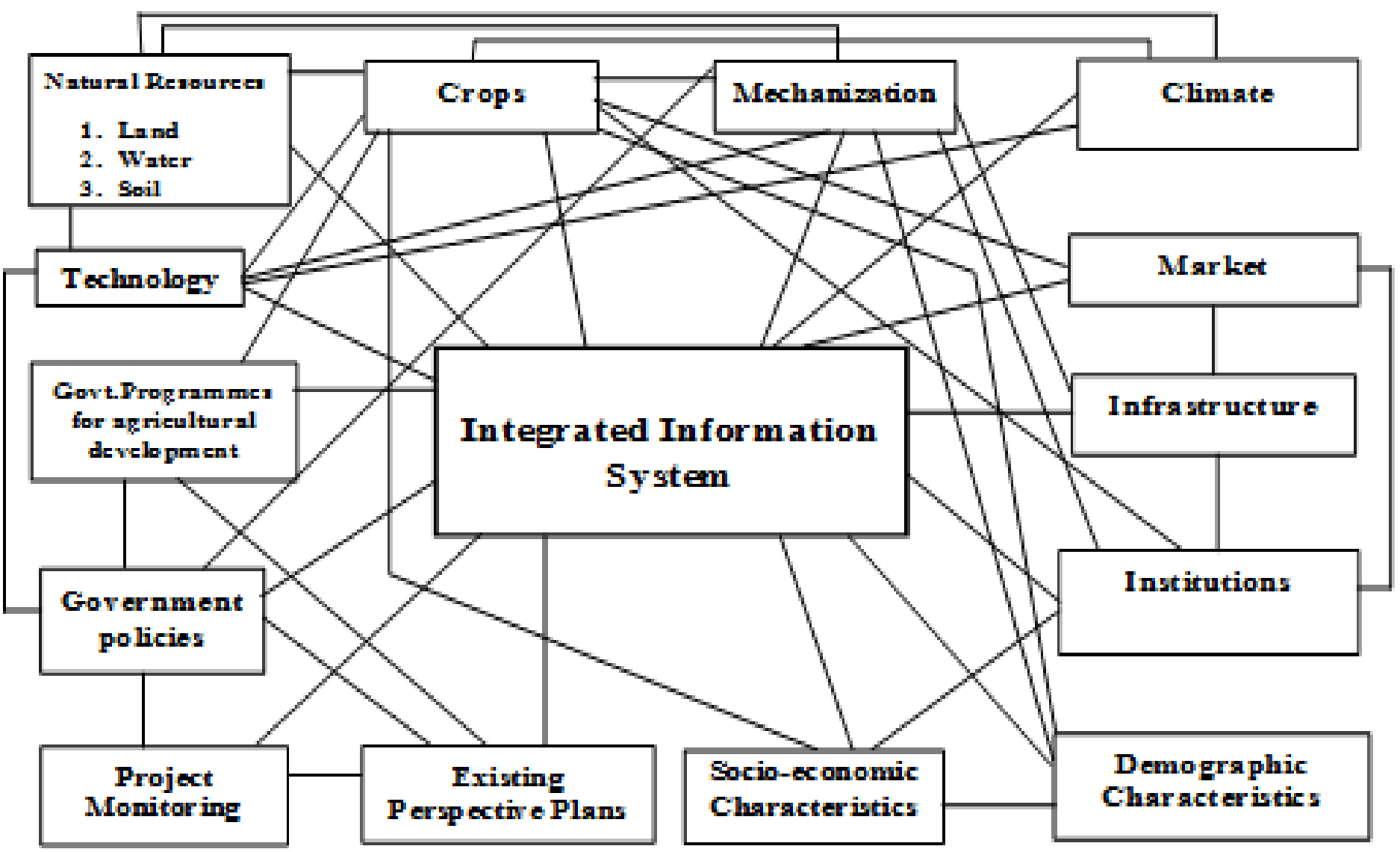


Fig.2 Overall information requirement of stakeholders in micro level planning

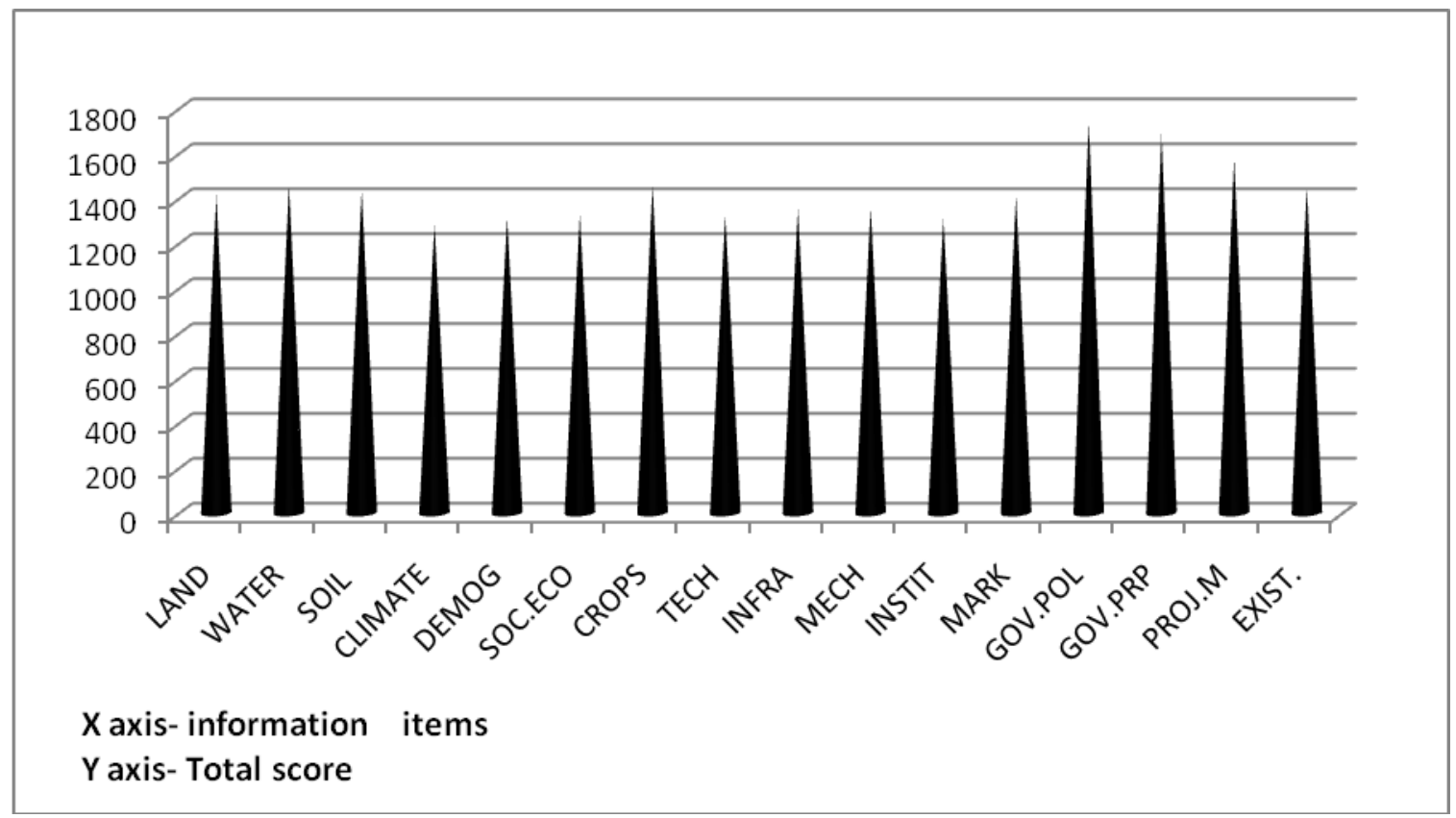

However, while considering the mean rank scores, the dimension of 'usability' was perceived to be of more importance, followed by 'comprehensiveness'. Spatial and temporal orientation was ranked after this and 'updatability' scored the lowest rank.

The test statistic was found to be significant showing that People's Representatives had the same set of perception levels with regard to these four dimensions. Among the four dimensions, People's Representatives perceived 'usability' as the most important of all the other dimensions. It was followed by 'comprehensiveness', 'spatial and temporal orientation' and 'updatability' in the decreasing order of importance. These results clearly showed the preference of attributes of an integrated information system for micro level planning, which shall be highly useful in designing the functionalities of an integrated information system.

Micro level planning in agriculture is a sustainable development concept which is information and data intensive activity.
However, in practice, the process of micro level planning is not supported with adequate data. The stakeholders of micro level planning at local bodies do not depend much on micro level data to formulate development plans. But several databases are being collected and maintained by government offices in their day-to-day activities. The information required for micro level planning can be easily met by the data generated by them. Since quality of micro level planning can be improved by using data support, it would be appropriate to develop an Integrated Information System which can ensure ready access to data at the micro level. This information system shall contain all possible information on natural resources, financial resources, inputs, technology, human resources and so on. The information system can also be oriented spatially and temporally so that micro level planning becomes more efficient. The different data domains are classified under 14 subheadings which include 233 data components. While analysing the data sources, we could see that 61 per cent of required data is being provided by the duo 
(panchayat and department of agriculture). Only 6 per cent of the information requirement is not readily met by different information sources. An analysis on the pattern of information requirement of Extension Personnel and People's Representatives shows that information on government policies was perceived as the most needed and valuable data for micro level planning. 'Comprehensiveness', 'Usability', 'Updatability' and 'Spatial and temporal orientation' were selected as the four dimensions of the proposed integrated information system.

\section{Acknowledgements}

We express our sincere gratitude to Kerala Agricultural University, Kerala, India for facilitating this work as part of $\mathrm{Ph} D$ programme. We owe to Dr. Jayasree Krishnankutty, Dr. Binoo P. Bonny, Dr. S. Krishnan, Dr. Jose Joseph and Dr. V. Govindaru for their critical inputs and valuable suggestions throughout the study.

\section{References}

Alex J. P (2011) E- governance as a prerequisite for development, rhetoric and reality. Indian J. Social Work 72(4): 563-588.

Ghosh A, Ghosh P K and Dutta D (2011) Development of Spatial Databases for Sustainable Micro-level Planning of Chandanpur Mouria, Purulia, West Bengal. e-Travere. J. SpatialSci. 2(2), pp.10-20.

GOK [Government of Kerala] (2009) Report of the Committee for Evaluating
Decentralized Planning and Development. Government of Kerala, Thiruvananthapuram. 249p.

Harande YI (2009) Information services for rural community development in Nigeria. Library Phil. Practice. [on line]. Available http://digitalcommons.unl.edu/libphilpr ac/271. ISSN 1522-0222. [6 Feb.2014]

Harilal K N (2012), Planning as an Instrument of Politics? Rethinking the Methodology of Local Level Participatory Planning in Kerala. RULSG Occasional papers, Centre for development studies, Thiruvananthapuram.p.40.

Issac TMT and Franke R (2002) Local Democracy and Development. Rowman \& little field publishers, New York, 241 p.

Jackson- Smith D (2002) Planning for Agriculture in Wisconsin, A Guide for Communities. UW Cooperative Extension and Wisconsin Department of Agriculture, Trade, and Consumer Protection, $96 \mathrm{p}$.

Moni M (2010) Impact of Economic Reforms on Indian Agricultural Sector: Application of Geomatics Technology to Reduce Marginalization and Vulnerability of Small Farmers in India. Ministry of Information Technology, New Delhi. Available: www.gisdevelopment.net/application/ag riculture/production/agric0003.htm.[5M ar.2013].

NIC [National Innovation Council] (2014) Data for Development [on line]. Available: www.disnic.nic.in/ data for development.htm. [04 May 2018].

\section{How to cite this article:}

Sulaja, O. R. and Jiju P. Alex. 2021. Sustainable Development Planning in Agriculture: Development and utilization of an Integrated Information System. Int.J.Curr.Microbiol.App.Sci. 10(06): 295-303. doi: https://doi.org/10.20546/ijcmas.2021.1006.031 